\title{
Stability Assessment of Open Stope under Overlaying Mined-Out Regions at Modi Taung Gold Mine, Myanmar
}

\author{
Naung Naung1,2, Takashi Sasaoka1, Hideki Shimada1, Akihiro Hamanaka1, \\ Sugeng Wahyudi' ${ }^{1}$ Mao Pisith ${ }^{1}$ \\ ${ }^{1}$ Department of Earth Resources Engineering, Kyushu University, Fukuoka, Japan \\ ${ }^{2}$ No. 2 Mining Enterprise, Ministry of Natural Resources and Environmental Conservation, Nay Pyi Taw, Myanmar \\ Email:naung15r@mine.kyushu-u.ac.jp
}

How to cite this paper: Naung, N., Sasaoka, T., Shimada, H., Hamanaka, A., Wahyudi, S. and Pisith, M. (2018) Stability Assessment of Open Stope under Overlaying Mined-Out Regions at Modi Taung Gold Mine, Myanmar. International Journal of Geosciences, 9, 547-571.

https://doi.org/10.4236/ijg.2018.99032

Received: August 13, 2018

Accepted: September 24, 2018

Published: September 27, 2018

Copyright $\odot 2018$ by authors and Scientific Research Publishing Inc. This work is licensed under the Creative Commons Attribution International License (CC BY 4.0).

http://creativecommons.org/licenses/by/4.0/

\section{Open Access}

\begin{abstract}
Stability assessment is one of the most important issues in mining ground control. Mine development and/or production instability can cause production delay, loss of reserves, as well as injury to miners. Within the scope of this study, a series of open stope's instability under the influence of overlaying mined-out regions were carried out with different mining scenarios at Modi Taung gold mine which is operated by National Prosperity Gold Production Group Limited (NPGPGL) in Myanmar. NPGPGL has been developing stopes up to $150 \mathrm{~m}$ from the surface at Shwesin vein system, and the mining activities are going to continue to deeper levels to fulfill the ore mineral supply. Creating a new stope opening under overlaying mined-out regions is not easy considering the instability of mined-out regions can affect the stope. The instability of new stope opening is not only due to its own induced stress but also the strong influence by the mined-out regions situated on upper part of the stope. Therefore, the understandings of ground behaviors and failure mechanisms of new stope opening due to the influence of overlaying mined-out regions are paramount to be studied. This paper describes in detail the strength factor and failure zones under the overlaying mined-out regions with different mine conditions by using numerical simulations, 3D finite difference software (FLAC 3D).
\end{abstract}

\section{Keywords}

Failure Zones, FLAC 3D, Open Stope, Overlaying Mined-Out Regions, Stability Assessment

\section{Introduction}

Myanmar is richly endowed with mineral resources, such as gold, silver, copper, 
tin, tungsten and zinc that are underexplored and underexploited. Key mining areas have been operating both surface and underground across the country and most of the underground mines are being mined out at the easily accessible shallow places. Therefore, underground mining activities are going to continue to progress into deeper levels to fulfill the mineral supply. It has been well known that stress condition in deeper mine will be greatly changed and the mining process would be more complicated accordingly, particularly when it is operated under overlaying mined-out regions. Creating a new stope opening under overlaying mined-out regions is not easy considering the instability of mined-out regions can affect the stope. It has been proven that the stability of new stope opening situated under part of the mined-out regions is not only due to its own induced stress but also the influence by overlaying mined-out regions.

In general, every underground excavation requires an assessment of risk. It drives the designed miner to perform the risk assessment with the knowledge of rock mass conditions that are essential for stability of underground excavations. For this reason, evaluation of rock mass properties has become one of the most important stages in mine design and construction. The first step for describing rock mass is to examine rock mass properties determined by lithology, laboratory tests and field observation data. The second step is to determine the geotechnical information of rock mass for the purpose of rock engineering design, such as numerical modelling, analytical calculation, etc. Considering the importance of rock stability in stope opening under overlaying mined-out regions, field observation for lithology, geology and mining system at NPGPGL underground gold mine was conducted, and laboratory experiments were carried out to collect the geomechanical properties of rock mass, and the potential instability of open stope mining was investigated by using FLAC 3D numerical simulations.

\section{Brief Information of NPGPGL Gold Mine}

\subsection{General Background}

The NPGPGL gold mine at Modi Taung is situated $1200 \mathrm{~m}$ above sea level in approximately $150 \mathrm{~km}$ southeast of Mandalay and $385 \mathrm{~km}$ north of Yangon, in the eastern part of the Yamethin Township, central Myanmar as shown in Figure 1 . The company operates in the southern part of Block 10 concession which is previously conducted exploration works by Ivanhoe Myanmar Holding Ltd. (IMHL), a Canadian mining company, who acquired the exploration/mining lease from the government from August 1996 to August 2005. The NPGPGL starts this gold mine on September 2011 with total mine lease area of $24.71 \mathrm{~km}^{2}$. Estimated gold reserve is about $14,647 \mathrm{~kg}$ of $\mathrm{Au}$ (from unpublished report of IMHL) and current ore grade is approx. 7 - 10 ppm according to the NPGPGL.

\subsection{Regional Geological Settings}

The Modi Taung area of central Myanmar lies in the northern end of the slate belt which consists of a late Paleozoic slatey mudstone and sandstone, and this 




Figure 1. NPGPGL mine site's location map (source: NPGPGL).

slate belt extends southwards through southern Myanmar, southwestern Thailand and central Sumatra. The geology of the slate belt in Block 10 concession previously operated by IMHL consists of the Kogwe mudstone and overlaying Poklokkale Pebbly Wacke. The NPGPGL gold mine is located at southern part of Block 10 area as shown in Figure 2. Almost all of the auriferous veins in Block 10 concession lie within the $25 \mathrm{~km} \times 5 \mathrm{~km}$ Modi Taung-Nankwe gold district with the feature characteristics of slate-hosted mesothermal quartz-gold vein deposits [1]. The deposit is hosted in the sedimentary units of the Mergui Group, which is composed of two dominant sedimentary formations. The lower part consists of massive to laminated mudstone, sandstone, rare limestone and channel-fill pebbly wackes while the upper part includes several polymict conglomerates. Veins within the gold distinct mostly strike $155^{\circ}$ to $180^{\circ}$ and mostly are very steep dipping [1].

\subsection{Lithology and Rock Mass Condition of NPGPGL}

Veins at Modi Taung gold mine are hosted by four main lithologies such as mudstone, sandstone-siltstone, limey sandstone or limestone, and igneous intrusions [1]. Mudstones are the predominant rock type in all vein system, but sandstone occupies short segments, and veins tend to occur along the inclined interface between sandstone and mudstone. Their competence and hardness increase with depth from soft clay immediately beneath soil cover to a hard rock 




Figure 2. Geology map of Block 10 and NPGPGL mine site (source: 2005 IMHL report, unpublished).

that is tough and competent except for moderate hardness near and below the base of the oxide zone. Sandstone and siltstone are mostly silicified and cut by quartz stockworks, forming quartzite. They are mostly intensely fracture, and hence brittle. Ground conditions are poor in Shwesin vein system and within 60 $\mathrm{m}$ from surface where partial oxidation has occurred [2].

At NPGPGL gold mine, Htongyi Taung and Sakangyi vein systems are hosted by mudstone, while the host rocks in the Shwesin, Sakangyi and Momi Taung systems are predominantly mudstone or siltstone and the rest sandstone [1]]. Veins in east of the least area are dipping steeply to the west, while veins in the west are dipping steeply to the east. Each vein system consists of either a single vein, or multiple parallel vein separated by host rock. Vein width varies with elevation and ranges between centimeter and meter scale. The detail geological structure of NPGPGL is shown in Figure 3 [3].

Currently, most of the shallow parts at Shwesin vein system of NPGPGL have already mined-out. The mining activities are going to continue to progress toward deeper levels to fulfill the target ore production. Therefore, rock mass 


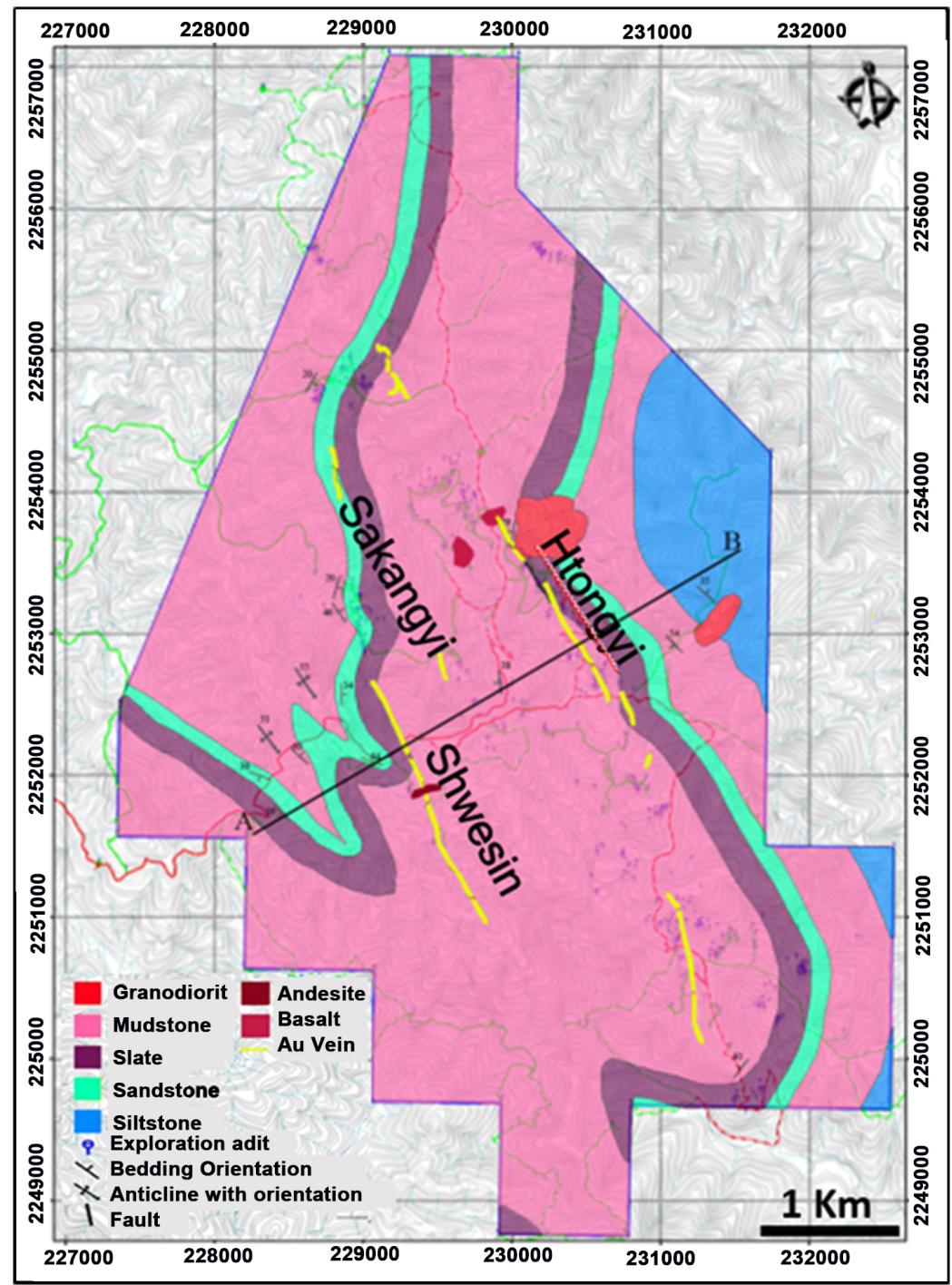

Figure 3. Geological structure of NPGPGL [3].

condition at deeper area should be investigated for stability of the excavation of new stopes. From the borehole data, the RQD value for different depth of NPGPGL gold mine is shown in Figure 4. Moreover, the correlation between RQD percentage and rock mass quality is shown in Table 1 [4]. According to the RQD data, the rock mass of NPGPGL can be classified as fair condition and some activities such as discontinuities, persistence, aperture, rock roughness, and weathering of rock are conducted to complete full estimation of rock mass condition. Furthermore, rock mass parameters that obtained from laboratory experiments are given in Table 2. It is shown in the table that the uniaxial compressive strength of intact host rock and vein from NPGPGL gold mine are 148 $\mathrm{MPa}$ and $140 \mathrm{MPa}$, respectively.

According to these intact rock parameters, it can be seen that the rock mass strength from NPGPGL gold mine is strong. In spite the fact that, without the consideration of geological structure, rock mass properties are not properly 


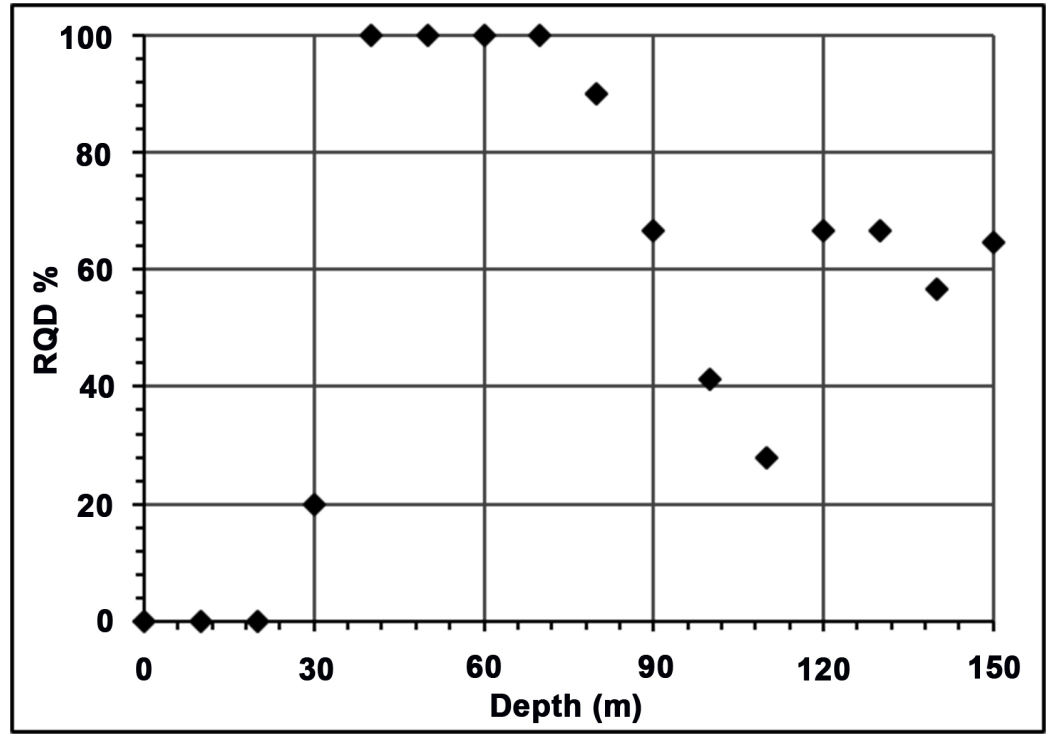

Figure 4. RQD and depth at Shwesin vein of NPGPGL (source: NPGPGL).

Table 1. RQD classification index [4].

\begin{tabular}{cc}
\hline RQD & Rock mass quality \\
\hline$<25 \%$ & Very poor \\
$25 \%-50 \%$ & Poor \\
$50 \%-75 \%$ & Fair \\
$75 \%-90 \%$ & Good \\
$90 \%-100 \%$ & Excellent \\
\hline
\end{tabular}

Table 2. Intact rock properties obtained from laboratory experiments.

\begin{tabular}{ccccccc}
\hline & $\begin{array}{c}E C S \\
{[\mathrm{MPa}]}\end{array}$ & $\begin{array}{c}E \\
{[\mathrm{MPa}]}\end{array}$ & $\begin{array}{c}V \\
{[-]}\end{array}$ & $\begin{array}{c}\sigma_{t} \\
{[\mathrm{MPa}]}\end{array}$ & $\begin{array}{c}\varphi \\
{[\mathrm{deg}]}\end{array}$ & $\begin{array}{c}C \\
{[\mathrm{MPa}]}\end{array}$ \\
\hline Host rock & 148 & 19,000 & 0.25 & 10.4 & 58 & 18.5 \\
Vein & 140 & 12,000 & 0.22 & 3.8 & 71 & 11.1 \\
\hline
\end{tabular}

applicable for any form of analysis for the design of slopes and underground excavations. Regarding this case, the Geological Strength Index (GSI) introduced by Marinos and Hoek, 2005 [5] is very essential to estimate the rock mass strength for different geological conditions. From the field observation at NPGPGL gold mine, many cracks and joints within rock mass are found in underground tunnels and stopes as shown in Figure 5. Additionally, heavy rainfall is one of the causes of weathering of rock mass. The rate of water charge increases after periods of heavy rain which is common for this area. This meteoric water interacts with the surrounding rocks which result in weathering of host rocks, leading to strength reduction of host rocks. All these conditions will give effect to the instability of underground excavations and should be paid attention to prevent the opening collapse. Consideration of rock mass condition including 




Figure 5. Rock mass condition in underground tunnel showing joints and cracks.

several factors such as RQD, joint spacing, the condition of joints, and weathering, the evaluation of NPGPGL rock mass properties from intact rock properties are shown in Table 3.

\subsection{Mine Condition}

The accessible shallow area has been already mined out at Shwesin vein system of NPGPGL, subsequently the deposits are left in deeper regions. Therefore, the company is planning to mine out the deeper area which are separated into 6 blocks, namely from block 1 to block 6 . The overall mine plan is illustrated in Figure 6. The company adopts overhand cut and fill method to extract the minerals at Shwesin vein system. The waste rocks from excavation are only used to both fill the stope and provide permanent wall support for the lower mine out cavity. Vein orientation within Shwesin vein system is as shown in Figure 7 and vein dipping are more than 50 degrees. Vein width varies with elevation and ranges between centimeter and meter scale [3].

\section{Description of Numerical Modelling and Mining Plan}

Numerical simulation is an effective way to examine the stability of a stope. In this study, the failure conditions of new stope opening because of overlaying 
N. Naung et al.

Table 3. Rock mass properties evaluated with geological conditions.

\begin{tabular}{cccccc}
\hline & $E[\mathrm{MPa}]$ & $v[-]$ & $\sigma_{t}[\mathrm{MPa}]$ & $\varphi[\mathrm{deg}]$ & $C[\mathrm{MPa}]$ \\
\hline Hanging wall & 3786 & 0.23 & 0.035 & 44 & 0.761 \\
Foot wall & 3786 & 0.25 & 0.065 & 40 & 0.687 \\
Vein & 3786 & 0.22 & 0.034 & 45 & 0.77 \\
\hline
\end{tabular}

\section{Longitudinal Profile For Shwe Sin Vein System and Estimated Western Ore Reaource Zone Map}

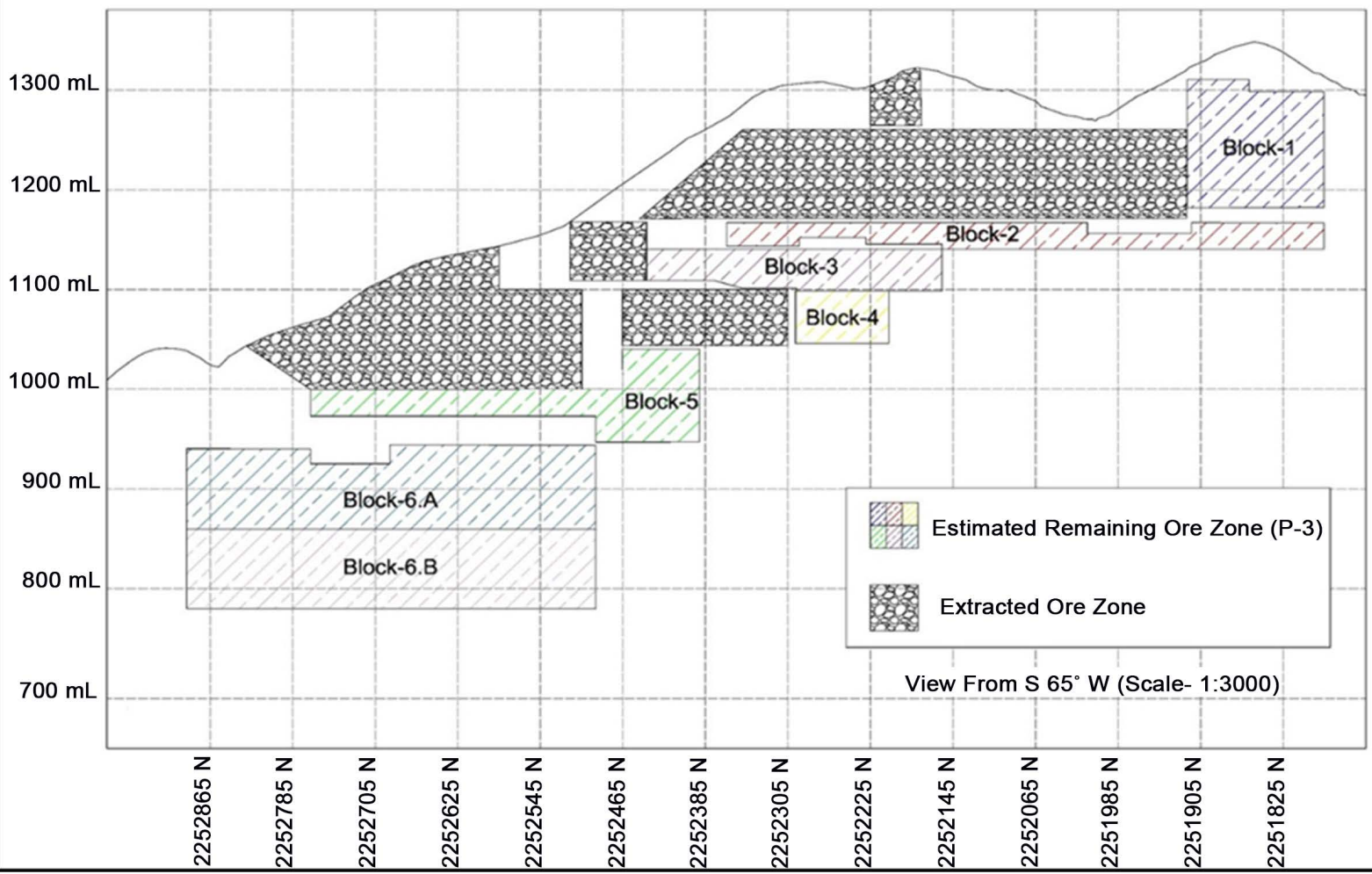

Figure 6. Simplified mine plan at Shwesin vein system (source: NPGPGL).



Figure 7. Shwesin vein orientation system [3]. 
mined-out regions were investigated by using the 3D finite difference code (FLAC 3D) for preliminary study. FLAC 3D is a numerical software which is widely used for analyzing stress and deformation around the surface and underground openings conducted in both soil and rock. The size of the basic numerical model is $250 \mathrm{~m} \times 250 \mathrm{~m} \times 250 \mathrm{~m}$ with 70 degrees in vein dip as shown in Figure 8 and mining plan is as shown in Figure 9. Additionally, the stope dimension is $2.5 \mathrm{~m}$ in height and $2 \mathrm{~m}$ in width, and the stoping sequence takes place from the lower slice to upwards direction. As described in lithology, the slaty mudstone is a dominant rock type in the NPGPGL gold mine, and therefore, the hanging wall and footwall are assigned as homogenous model for simplification. The mechanical properties of host rock and vein are given in Table 3. Moreover, to obtain more precise result of the rock failure distribution, the smaller mesh size was selected around the excavation area. In the simulations, the overhand cut and fill mining from the lower slice of the vein of block 2 was conducted as shown in Figure 9. Block 2 is the planned mine area with $24 \mathrm{~m}$ in height under overlaying mined-out regions with $100 \mathrm{~m}$ in height, and the total overburden above block 2 is $150 \mathrm{~m}$. This study is carried out for the stability of current stope opening in block 2 in various mining conditions which is not only influenced by its own induced stress but also affected by overlaying mined-out area.

\section{Failure Criterion}

Mining objective is to recover ore as much as possible from the vein. However, safety of worker and machinery in the advancing stopes must be ensured. Potential hazards in the stopes are rock falls from the stope's roof and buckling failures in the hanging wall and footwall. In order to stabilize the stope, a failure criterion must be selected. A factor of safety of 1.3 would generally be considered as a stability standard for a temporary mine opening while a value of 1.5 to 2.0 may be required for a permanent excavation [6]. However, the selection of an



Figure 8. Basic numerical model. 


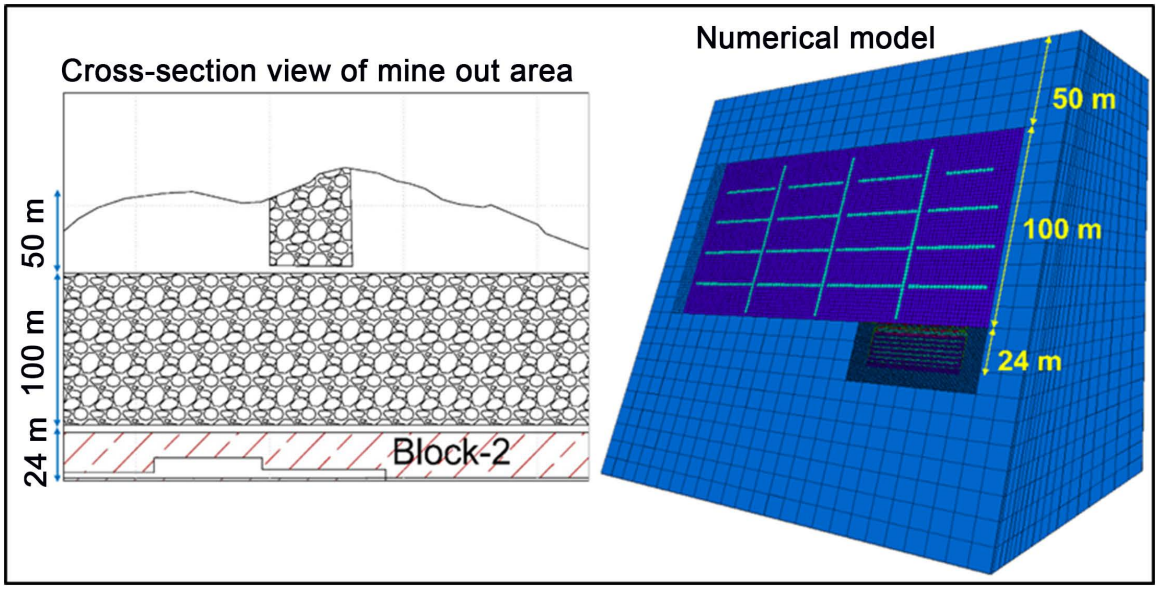

Figure 9. Overhand cut and fill mine plan at Shwesin vein.

appropriate factor of safety is based upon engineering experience and field observation. In this research, the Mohr-Coulomb failure criterion is adopted as shown in Figure 10 and elasto-plastic behavior of the rock mass is used. The strength factor (factor of safety) is calculated by dividing the strength of rock mass by the induced stress of stoping activities to provide a basis of stability assessment as follows [7]:

$$
\text { Strength factor }=\left\{c \cos \varphi+\left[\left(\sigma_{1}+\sigma_{3}\right) / 2 \times \sin \varphi\right]\right\} /\left[\left(\sigma_{1}-\sigma_{3}\right) / 2\right]
$$

Strength factor (safety factor) of 1.3 is adopted for temporary stope mining. The stope was considered in a stable condition when Mohr-Coulomb strength factor is greater than 1.3 and unsatisfactory condition will meet when strength factor is less than 1.3.

\section{Results and Discussions}

In general, no one can estimate the rock mass is stable or not without numerical simulations. Determining the tunnels and stopes are stable or unstable should be based on yield zones from numerical simulations. Therefore, to understand the instability of stope opening under overlaying mined-out regions, numerical simulations were firstly conducted for the stope without overlaying mined-out effects compared with simulations for the stope with overlaying mined-out effects. Additionally, for more understanding of stope's instability under overlaying mined-out regions, numerical simulations have been observed with various mine conditions such as different vein dips, different vein widths, different stress ratios, different geological conditions and different backfilling. The explanations of failure terms given in the legend in Flac 3D are as follows [8]:

1) "none" indicates no-failure zone,

2) "shear-n" indicates the region failed under shear loading and failure process is still in progress,

3) "shear-p" indicates the region failed under shear loading and failure process is stopped due to lowered amount of shear forces. 


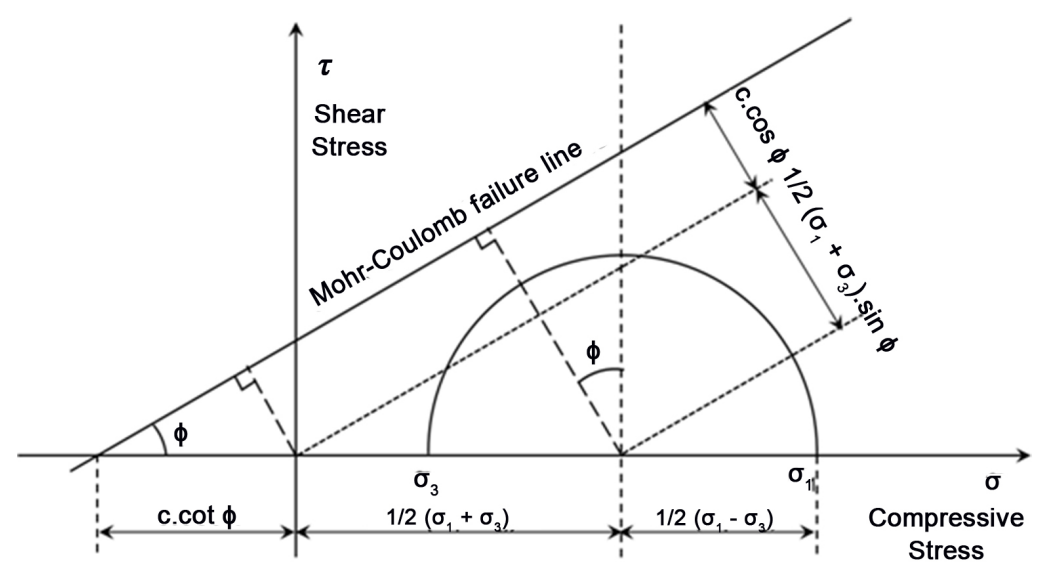

Figure 10. Mohr-Coulomb failure criterion.

4) "tension-n" indicates the region failed under tensile loading, and failure process is still in progress,

5) "tension-p" indicates the region failed under tensile loading, and failure process is stopped due to lowered amount of tensile forces.

\subsection{Stability Assessment for the Influence of Overlaying Mined-Out Regions}

First, numerical simulations were carried out with the aim to understand the stability of stope due to the influence of overlaying mined-out regions. Figure 11 shows the failure zone which occurred around the stope without the influence of overlaying mined-out. Whereas, Figure 12 shows the failure zone developed with the influence of overlaying mined-out. Based on the simulation results which are shown in Figure 11, the failure zone around the stope increases steadily as the stope progresses move towards upper slices. These trends tell that failure zone of current stope is accumulated to the next stope. Compared with the failure condition under the influence of the overlaying mined-out effects as shown in Figure 12, the failure characteristics of surrounding rock masses as shown in Figure 12 are larger than that of in Figure 11. The statement can be addressed from these two results that the redistributed stresses from overlaying mined-out regions are surely propagated to the current stope mining activities. As a result, the development of failure zone of current stope room is increased. The increase is not only due to its own induced stress but also affected by the redistributed stresses of overlaying mined-out regions. Additionally, the instability of the barrier pillar near the overlaying mined-out regions became more severe when the stope mining reaches to the uppermost level (i.e. the nearest stope to the upper mined-out regions).

In this analysis, the height of barrier pillar is set to $2 \mathrm{~m}$ between the final stope and upper mined-out regions considering the current condition of barrier pillar at NPGPGL mine site. Figure 13 proved the description by showing that the strength factor indicator gradually decreases as the mining steps increase 


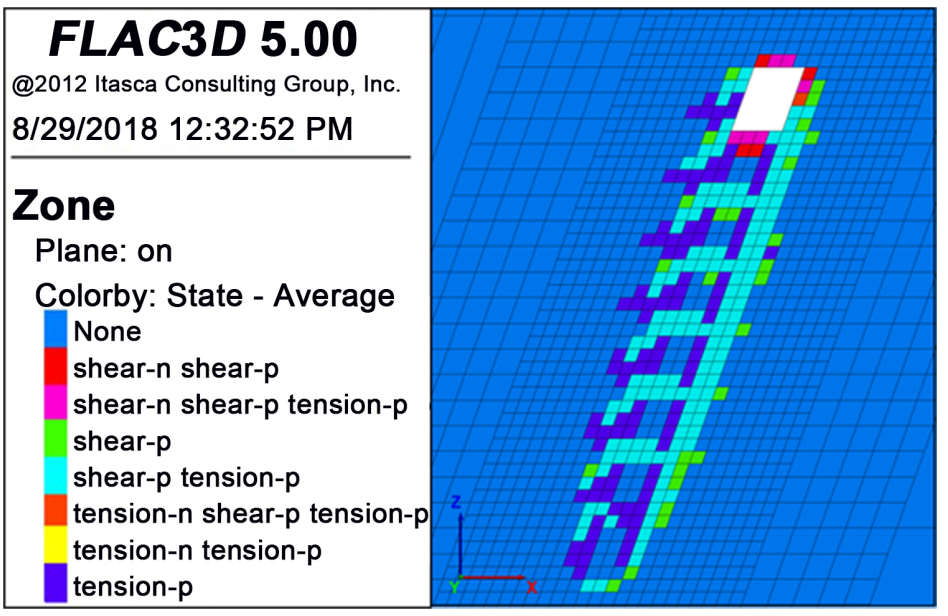

Figure 11. Failure zone developed without overlaying mined-out effects.



Figure 12. Failure zone developed with overlaying mined-out effects.

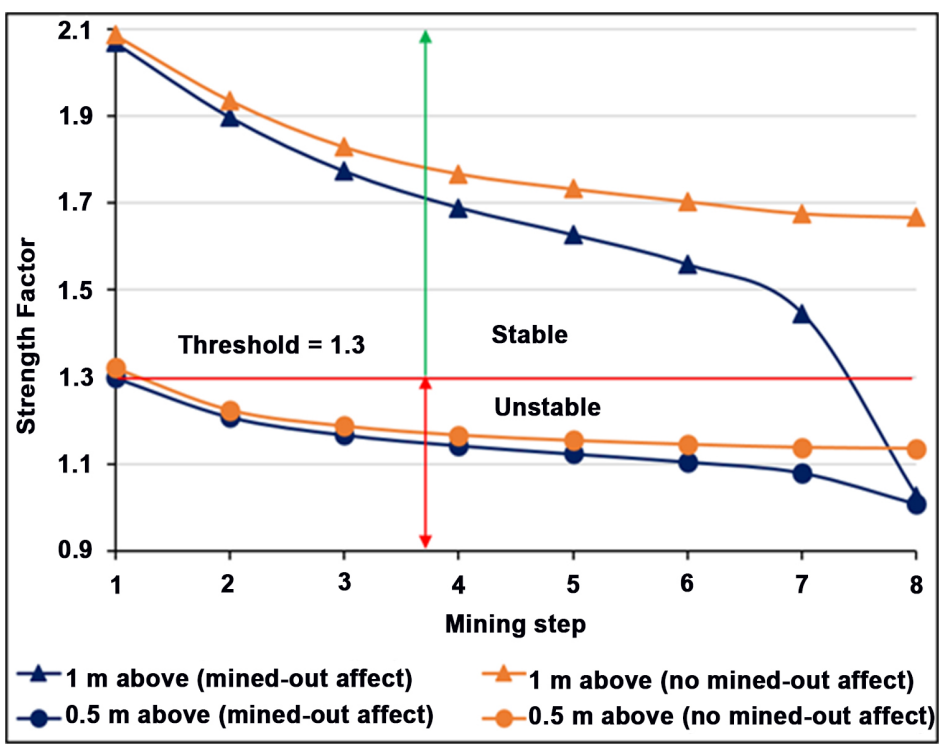

Figure 13. Strength factor indicators from $0.5 \mathrm{~m}$ and $1 \mathrm{~m}$ above the stope's roof at various mining steps. 
(i.e. from the base to top of the stoping sequence). This result suggests that decrease in strength factor makes increase in instability area around the stope opening. As roof stability is primarily determined in many underground mines especially in the presence of structural discontinuities, the monitoring points for these indicators are placed $0.5 \mathrm{~m}$ and $1 \mathrm{~m}$ above the center of stope's roof. Based on the graph's result, the instabilities had appeared in $0.5 \mathrm{~m}$ above the stope's roof and it had been occurred a stable condition above $1 \mathrm{~m}$ from the stope's roof except the uppermost stope near the overlaying mined-out regions. For this sense, the numerical simulations for the stability of barrier pillar are conducted to understand the possibility of unstable regions with different barrier pillars and determine the appropriate barrier pillar to avoid rock falls from the stope's roof.

\subsection{Stability of Barrier Pillars with Its Heights}

At Shwesin vein system from NPGPGL underground gold mine, the barrier pillar height is broadly maintained $2 \mathrm{~m}$ between the top stope and overlaying mined-out regions. As explained in previous section, the failure zone at the barrier pillar had been propagating to overlaying mined-out regions. Therefore, numerical simulations with different barrier pillar heights $(2 \mathrm{~m}, 2.5 \mathrm{~m}, 3 \mathrm{~m}$ and $3.5 \mathrm{~m}$ ) were carried out to confirm the stability of the barrier pillar. Figure 14 shows that the failure conditions of barrier pillar with different pillar heights and Figure 15 indicates the unstable regions around the stope room shown by contour color of strength factor. These results suggest that the failure zones and instabilities of top stope continue to the overlaying mined-out regions when the barrier pillar is set to $2 \mathrm{~m}$ in height, and decrease gradually when the height of barrier pillar increases to $2.5 \mathrm{~m}, 3 \mathrm{~m}$ and $3.5 \mathrm{~m}$ continuously. According to these results, the unstable regions are still propagated to the upper mined-out failure zone when the barrier pillar height is set to $2.5 \mathrm{~m}$ in height. However, this condition did not continue when the barrier pillars are set to $3 \mathrm{~m}$ and $3.5 \mathrm{~m}$ in height. Therefore, these results suggest that the barrier pillar between the top stope and overlaying mined-out regions should be maintained at least $3 \mathrm{~m}$ in height to ensure stability of barrier pillar. Additionally, the potential of buckling failures from the hanging wall and foot wall should be paid attention to prevent rock falls from the side walls of the stope.

\subsection{Stability Assessment of Stope under Various Geological Conditions}

Simulations for various geological conditions were carried out to understand the instability of open stope due to the influence of different geological conditions under overlaying mined-out regions. Geological conditions are represented by Geological Strength Index (GSI) parameter [5]. As mentioned above, the rock structure of NPGPGL consists of many cracks and joints, and the rock mass is categorized as fair condition according to the RQD data. Rock mass properties are changed with geological condition as the basis, and all rock mass properties 


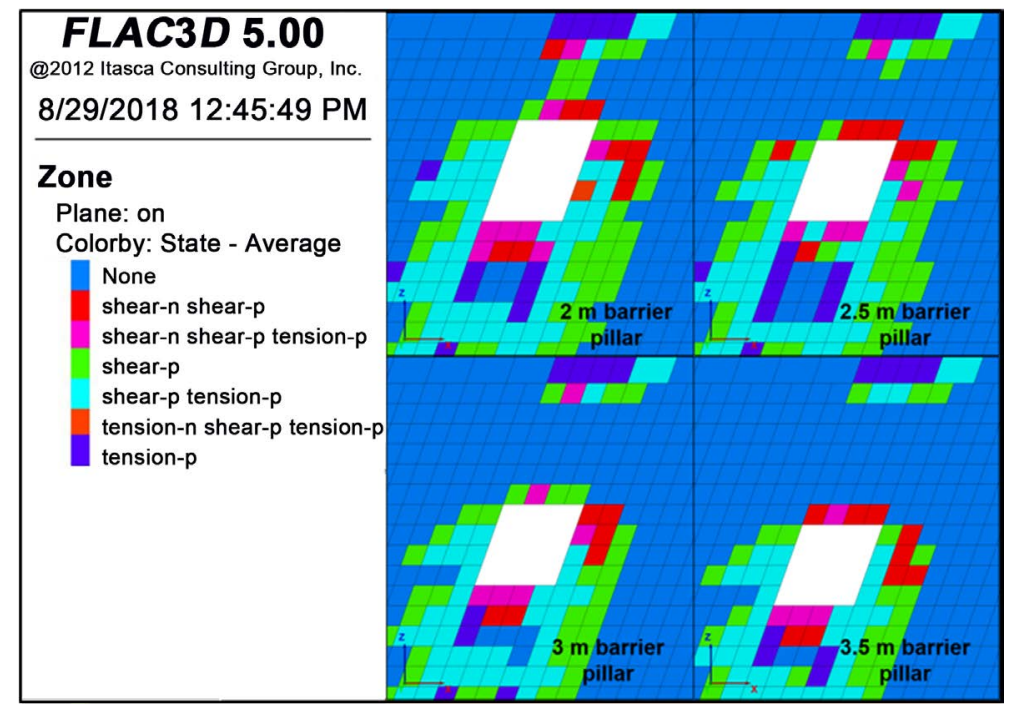

Figure 14. Failure zones of barrier pillars with different pillar heights.

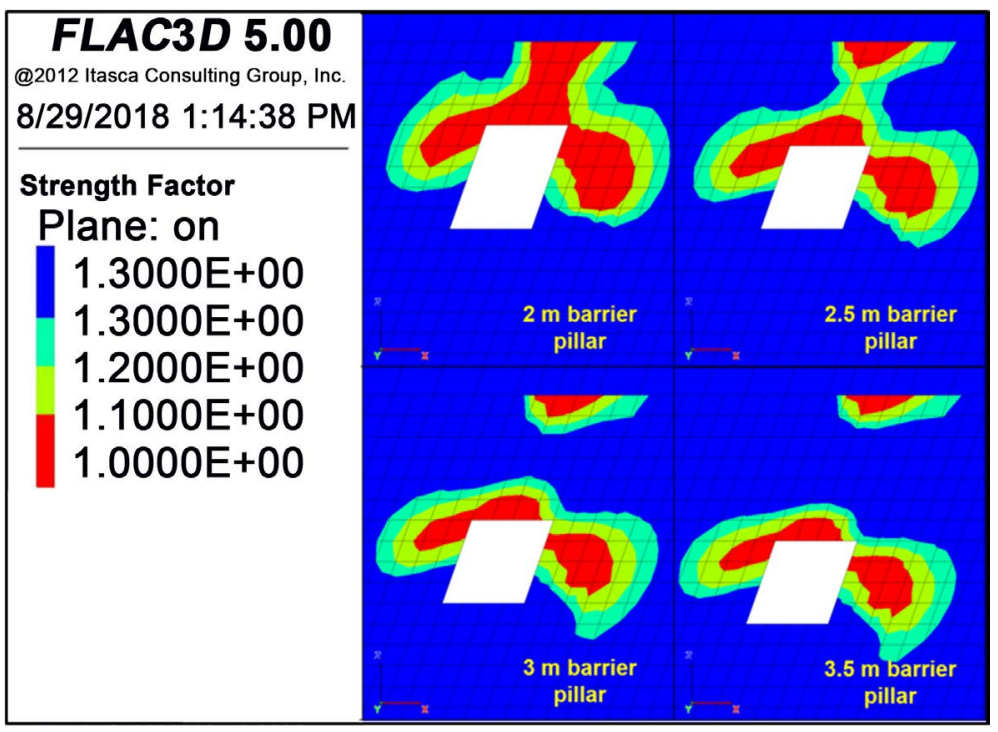

Figure 15. Contour color of unstable regions of barrier pillar with different pillar heights.

were determined for each GSI by using Hoek and Brown Failure Criterion [9]]. In order to understand the effect of different geological conditions, numerical simulations were conducted with the various GSI numbers ranging from 39, representing blocky/disturbed/seamy rock mass folded with angular blocks formed by many intersecting discontinuity sets, to 49 , representing very blocky rock mass with interlocked partially disturbed rock mass [10]. Figure 16 displays the failure zone occurred around the stope with different GSI numbers. Whereas, Figure 17 indicates the unstable area which is shown by the contour color of strength factor around the stope and Figure 18 shows the strength factor index from the stope advancing activities that are monitored from $0.5 \mathrm{~m}$ and $1 \mathrm{~m}$ above the stope. 


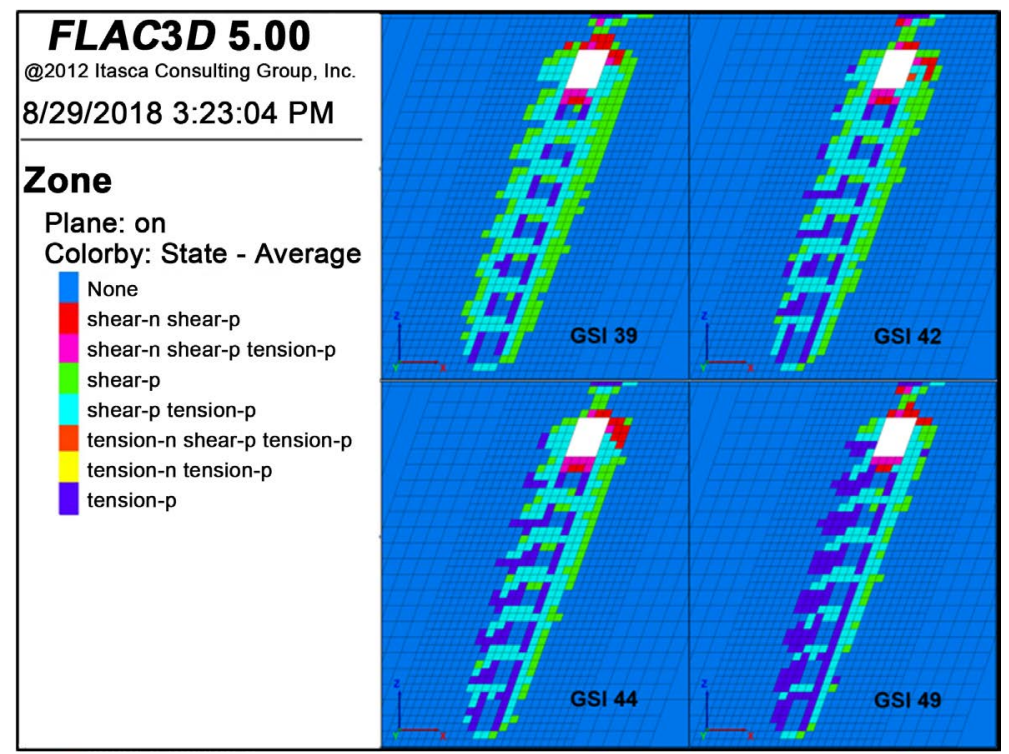

Figure 16. Failure zones around the stope with various geological conditions.

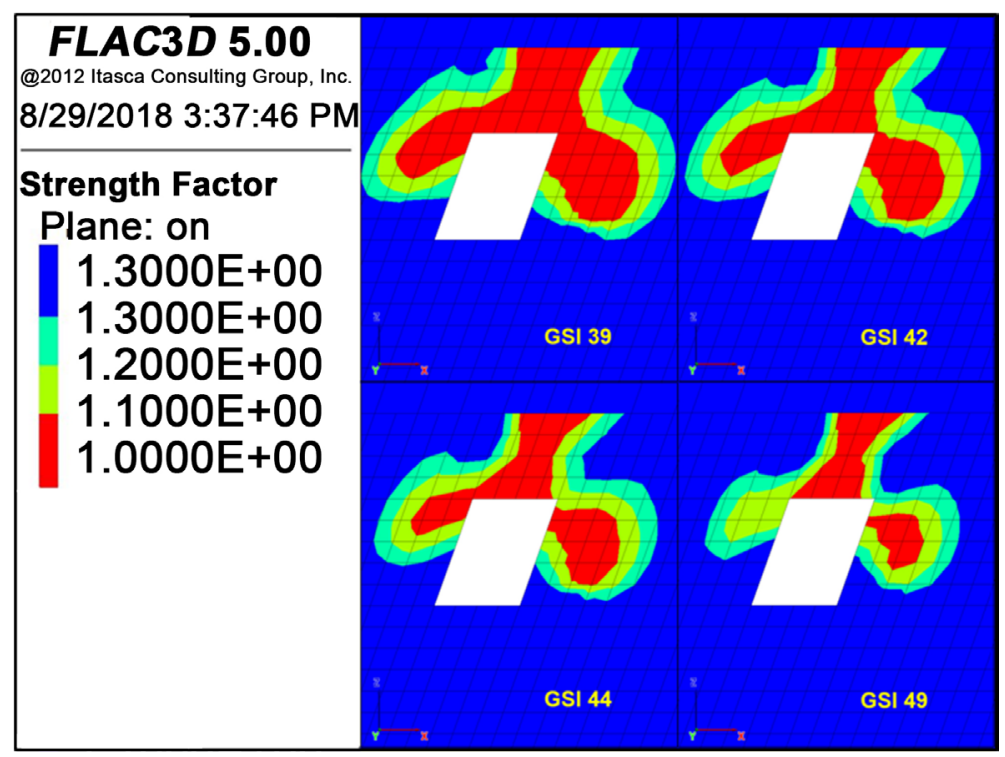

Figure 17. Contour color of unstable regions around the stope with various geological conditions.

The results suggest that the geological conditions become more severe with decrease in GSI, the potential of failure zones around the stope is higher for lower GSI value. Accordingly, the unstable regions became larger as the rock mass structure characterizes in weaker condition. In addition, the strength factor index of stope in every mining step that tells the unstable conditions were occurring in $0.5 \mathrm{~m}$ above the stope's roof and it will reach a stable condition in $1 \mathrm{~m}$ above the stope except the top stope. All these results pointed out that rock mass structure characterized with cracks and joints and meteoric water which result in weathering of host rock will give effects to the instability of underground excavations. Therefore, it should be paid attention for the stability of stope opening if 




Figure 18. Strength factor index from stope advancing in various geological conditions.

the geological condition of rock mass is severe condition, not only for safety but also for production losses due to ground collapses.

\subsection{Stability Assessment of Stope with Different Vein Dips}

As described above, vein dips are greater than 50 degree in NPGPGL mine site. Therefore, numerical simulations are carried out in various vein dips with the aim to understand the stope's stability under the overlaying mined-out regions in different vein dips. The simulation models are divided into three different vein dips including 60 degree, 70 degree and 80 degree. Apart from different vein dips, all models are simulated using the same properties. The simulation results of the stope are shown in Figure 19, Figure 20 and Figure 21.

Figure 19 indicates that the failure zones are more likely to occur with lower vein dip especially in hanging wall and foot wall region/area. On the other hand, the failure zones above the stope opening increase as the vein dip increase. Figure 20 shows the contour color code of unstable regions around the stope due to various vein dips and Figure 21 demonstrates the graph of strength factor index monitored at $0.5 \mathrm{~m}$ and $1 \mathrm{~m}$ above the stope's roof in every mining steps. It can be seen clearly that the unstable regions are more severe in hanging wall and foot wall with lower vein dip while the instability become more develop above the stope opening with steeper vein dip, and the stope will reached a stable condition at $1 \mathrm{~m}$ distance from the roof except the adjacent stope to the overlaying mined-out area. Thus, all results suggest that special attentions need to be given on hanging wall and foot wall when mining activities conduct at lower vein dip condition.

\subsection{Stability Assessment of Stope with Different Stope Widths}

Within the Modi Taung area, most veins trend north-northwesterly and each vein system consists of either a single vein, or multiple parallel vein separated by 




Figure 19. Failure zones around the stope due to various vein dips.



Figure 20. Contour color of unstable regions around the stope due to various vein dips.



Figure 21. Strength factor index due to various vein dips.

host rocks [1]. The vein systems have many splits, and in most crosscuts consist of two or more narrow veins or veinlets. Vein width varies with elevation and ranges between centimeter and meter scale. For the extraction of all veinlets in this mine site, the wider stopes might be needed to increase the ore extraction to the maximum. For this reason, numerical simulations are conducted with various stope widths $(2 \mathrm{~m}, 3.5 \mathrm{~m}$ and $5 \mathrm{~m})$. All stability analyses of each stope are carried out under overlaying mined-out area. The simulation results shown by the failure zones and strength factor are given in Figure 22, Figure 23 and Figure 24.

The wider stope width can develop higher induced stress and instability which result serious consequences on the behavior of the stope opening. As can be seen 




Figure 22. Failure zones due to different stope widths.

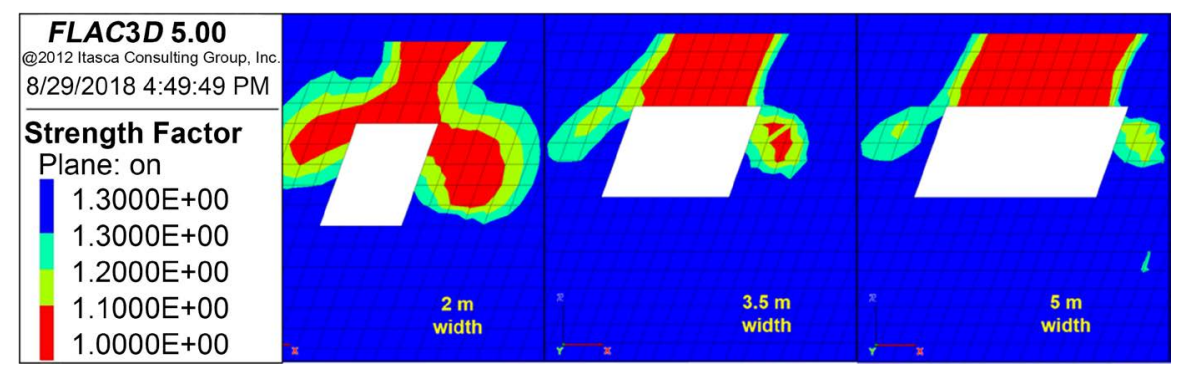

Figure 23. Contour color of unstable regions due to different stope widths.



Figure 24. Strength factor index due to different stope widths.

in Figure 22, the potential of failure zones are more likely to occur when the stope opening become wider especially in the roof of the stope opening. On the contrary, Figure 23 shows that the unstable area occurs more severe at the roof of wider stope opening. Consequently, the graph of monitoring points collected at $1 \mathrm{~m}$ above each stope's roof indicates that the wider stopes are unstable in all mining steps within $1 \mathrm{~m}$ above the stope's roof as shown in Figure 24. Thus, these results pointed out that the importance of stope stability when stoping activities carried out at wider vein width and the necessity of an appropriate support system around the wider stope since higher induced stresses are expected to redistribute to the surrounding rock mass. 


\subsection{Stability Assessment of Stope with Different Stress Ratios}

In underground mining, the pre-existing stress state changes dramatically due to excavation, therefore load must be redistributed. As mining progresses and more stopes are mined, stresses will be transferred to the remaining unmined stopes. Notably, near-by mining activity has a significant on the state of stress prior to mining a stope. As described in mining condition of NPGPGL, the accessible shallow area is already mined out at Shwesin vein system and the company plans to continue the mining activities at the deeper area located under previous mined-out regions. Therefore, analyzing over stress changing become one of the important issues for the stability of stope opening under previous mining condition in this underground mine. To assess this, three stress ratio $(K)$ conditions are simulated as a preliminary assessment of stope's instability under overlaying mined-out regions. Stress ratio less than one indicate a high vertical stress condition and a high horizontal stress condition will specify at the stress ratio above one. Figure 25 shows the spread of failure zones into rock mass around due to various stress ratios. Figure 26 depicts the strength contours of rock mass represented by strength factor around the stope's boundaries and Figure 27 indicates the strength factor index monitored at $1 \mathrm{~m}$ above the stope's roof. In addition. Figure 28 describes the stress flow condition relating to high vertical stress state and high horizontal stress state.

It can be observed in Figure 25 that the failure zones around the stope opening in higher stress ratio are more propagated than that in lower stress ratio. Figure 26 shows more clearly that the strength of rock mass will have more severe condition around the stope opening in high horizontal stress state. In addition, the graph of strength factor index shows that the rock mass maintains satisfactory condition at $1 \mathrm{~m}$ above the stope's roof in normal and lower stress ratio except the stopes near the upper mined-out area as shown in Figure 27. On the other hand, the stability of rock mass will have severe state since the $4^{\text {th }}$ slice to the uppermost slice at higher stress ratio.

The source of stope's instability upon the variation of stress ratios is due to the effect of stress flow path in the surrounding rock mass as shown in Figure 28. Since stress cannot flow through an opening, it must flow around the stope's boundaries. The stope opening causes an induced stress in tangential direction around the stope. Thus, the expected trend have been made to link the flow path

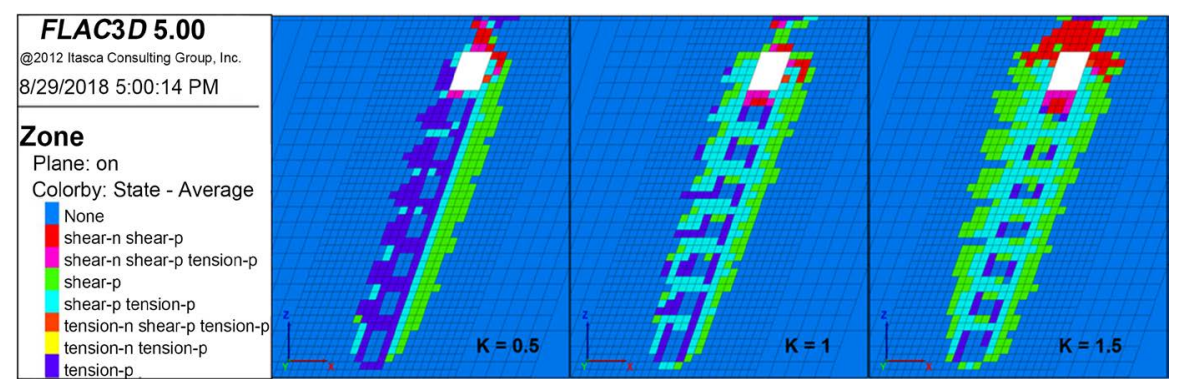

Figure 25. Failure zones due to different stress ratios. 




Figure 26. Contour color of unstable regions due to different stress ratios.

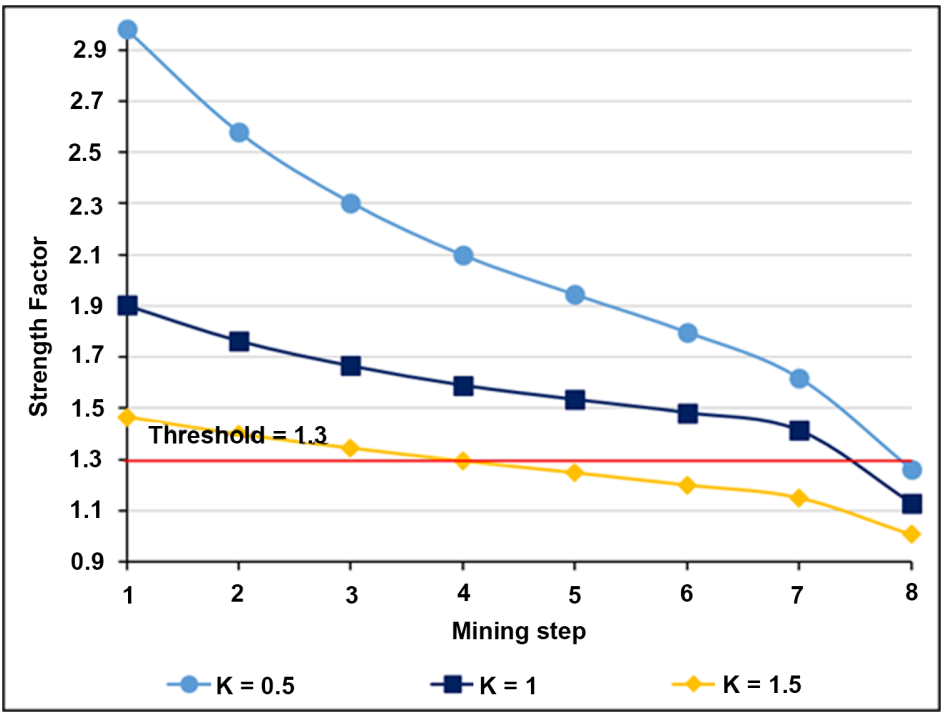

Figure 27. Strength factor index due to different stress ratios.


Figure 28. Stress flow for high vertical stress and high horizontal stress.

of the maximum field stress from the surrounding rock to the induced stress at the stope's boundaries. It can be seen in Figure 28 that the flow path of the maximum field stress pass through in line to the induced stress around the stope opening in lower stress ratio. When the stress ratio become larger, the tangential 
stress around the stope's boundaries are induced perpendicular to the maximum field stress, therefore the potential failures are expected more severe around the stope opening in high stress ratio.

\subsection{Stability Assessment of Stope with Different Backfilling Materials}

The placing of backfill underground has predominantly been a practice employed in cut and fill mines. Backfilling in open stope tends to prevent the deformation of the surrounding rock mass into the mined-out space and to provide a working platform as well. The common types of fill material are waste rock, tailing materials, sand, gravel and some additives. At NPGPGL underground mine, waste rocks from the stope advancing are used to provide a working platform and localized support. In this study, the numerical simulations were conducted under overlaying mined-out area with four different backfilling materials which are waste rock fill, hydraulic fill (mixture of $60 \%-80 \%$ solid in water), cemented paste fill (CPF) (cement-tailing ratio was 1:8) and cemented rock fill (CRF) (mixture of 5\% cement with waste rock) in different properties as shown in Table 4 [11] [12] [13] [14]. Figure 29 shows the result of failure zones with different backfilling materials. Figure 30 and Figure 31 express the strength factor conditions around the stope due to various backfilling materials.

According to the results from Figure 29, it is noted that the failure zones around the stope decrease as the strength/competence of backfilling materials increase. However, the potential of failure cannot clear for the stope stability even though the backfilling materials have stronger properties. It can be obviously found in the contour of strength factor as shown in Figure 30 that the unstable zones still appear in the vicinity of the stope despite the open stopes are loaded with stronger backfilling materials. In addition, Figure 31 indicates that the stopes will be unstable within $0.5 \mathrm{~m}$ above the roof and it will have a stable condition at $1 \mathrm{~m}$ above except the stopes near the upper mined-out area. According to these results, the deformation of the surrounding rock mass to the mined-out space can reduce depending on the properties of different backfilling materials, however, the unstable zones still occur. Therefore, the selection of backfilling material should be based on available backfill materials and economic factor only instead of stability reason.

Table 4. Properties of backfilling materials.

\begin{tabular}{cccccc}
\hline & $\begin{array}{c}\mathrm{E} \\
{[\mathrm{MPa}]}\end{array}$ & $\begin{array}{c}v \\
{[-]}\end{array}$ & $\begin{array}{c}\sigma \\
{[\mathrm{MPa}]}\end{array}$ & $\begin{array}{c}\varphi \\
{[\mathrm{deg}]}\end{array}$ & $\begin{array}{c}\mathrm{C} \\
{[\mathrm{MPa}]}\end{array}$ \\
\hline Hydraulic Fill & 181 & 0.2 & 0 & 6.9 & 0.07 \\
Waste Rock Fill & 153.1 & 0.321 & 0 & 20.5 & 0.200 \\
Cemented Paste Fill (CPF) & 1130 & 0.16 & 1.01 & 48 & 1.16 \\
Cemented Rock Fill (CRF) & 2850 & 0.34 & 0.7 & 25.4 & 1.4 \\
\hline
\end{tabular}






Figure 29. Failure zones in various types of backfilling materials.

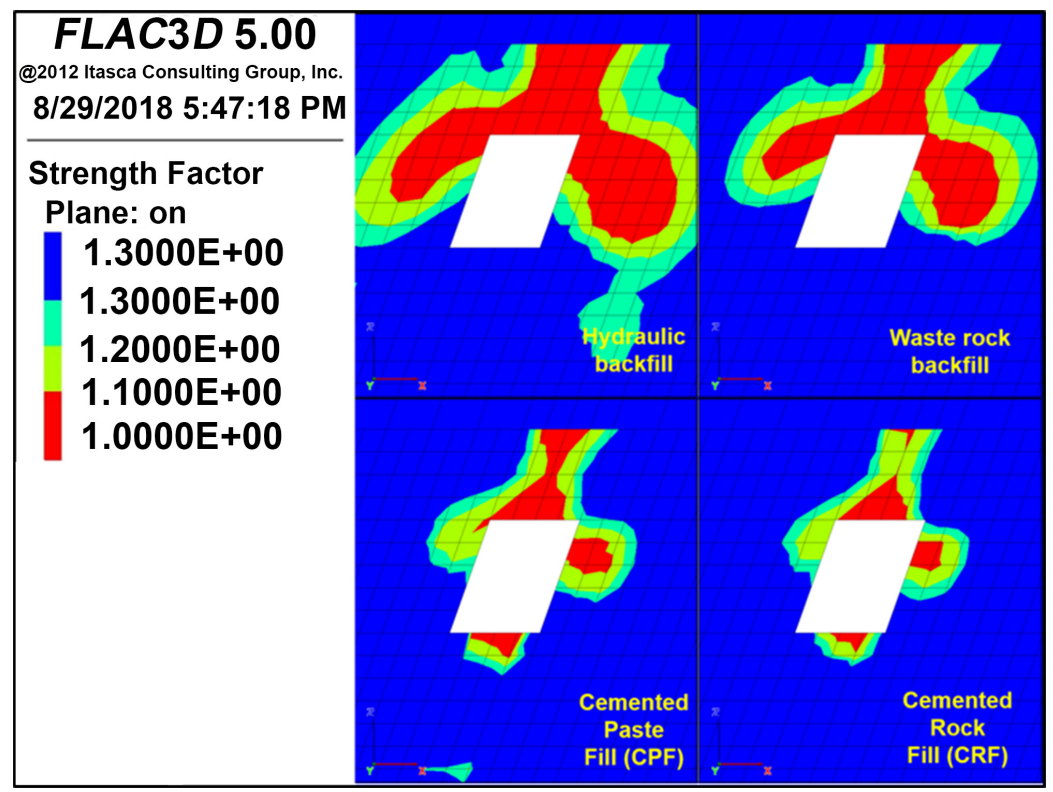

Figure 30. Contour color of unstable regions due to various types of backfilling materials.

\section{Conclusions}

The mining activities of NPGPGL underground gold mine continue to progress toward deeper levels to fulfill the target ore production according to their mining plan. Therefore, the potential failures from the overlaying mined-out regions to the new stope opening should be investigated to stabilize the stope and barrier pillar in various mine conditions. Risk-indexes, such as rock fracture, effect of underground water, weathering and stress redistribution from the previous mined-out area, etc. can be subjected to the current stope mining activities. 


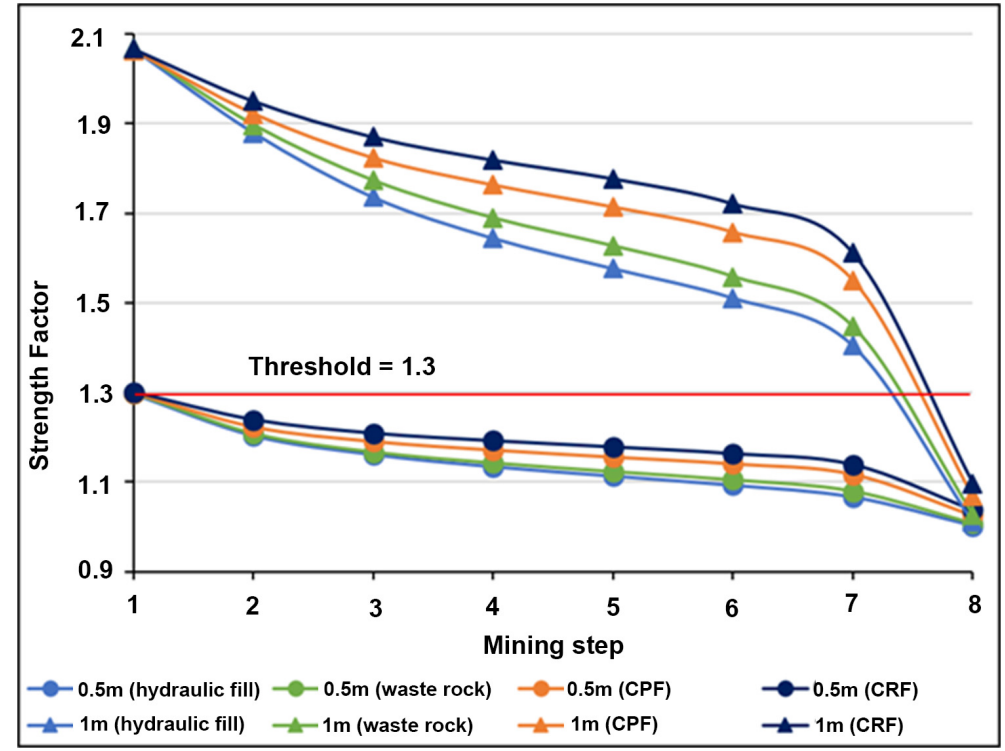

Figure 31. Strength factor index due to various types of backfilling materials.

The first state of this study consists of the determination of the geomechanical properties of the rock mass by means of field observation data and laboratory studies. For this purpose, several experiments were conducted at the laboratory, such as uniaxial compressive strength test, Brazilian tensile strength test, determination of density and Poisson's ratio, etc. In the second state, the potential of failure zones and instabilities at the stope's boundaries under the influence of previous mined-out regions were examined with different mine conditions, such as geological conditions, vein dips and widths, stress ratios and backfilling materials. In this paper, all assessments for the stability of stope are investigated numerically with three-dimensional finite difference code software, FLAC 3D.

The analysis results indicated that the failure zone and instability of the surrounding rock mass of stope increase steadily as the stope progressing moves toward upper slices and it propagates to the previous mined-out regions. Thus, the barrier pillar should be maintained at least $3 \mathrm{~m}$ in height to stabilize the stope and to prevent rock falls from the stope's roof and walls. Moreover, the potential of instability is likely to occur in the lower vein dips, more severe geological condition, wider vein width and higher stress ratio. Furthermore, the backfilling materials cannot clear the instability in the vicinity of the stope. Therefore, the selection of backfilling material should be based on available backfilling materials and economic factor only instead of stability reason. According to all simulation results, suitable countermeasure arrangements are paramount to be prepared by considering the stability of stope mining activities under the influence of overlaying mined-out regions.

\section{Acknowledgements}

The authors would like to acknowledge Japan International Cooperation Agency 
(JICA) for the project of human resources development in mining sector, namely KIZUNA program. We also wish to express our appreciation to NPGPGL gold mine for the permission to mine visit, usage of data and rock samples.

\section{Conflicts of Interest}

The authors declare no conflicts of interest regarding the publication of this paper.

\section{References}

[1] Mitchell, A.H.G., Ausa, C.A., Deiparine, L., Hlaing, T., Htay, N. and Khine, A. (2004) The Modi Taung-Nankwe Gold District, Slate Belt, Central Myanmar: Mesothermal Veins in a Mesozoic Orogen. Journal of Asian Earth Sciences, 23, 321-341. https://doi.org/10.1016/S1367-9120(03)00138-X

[2] IMHL. (2003) Production Sharing Proposal of IMHL. (Unpublished)

[3] Erskine, T.R. (2014) Geology, Structure and Mineralisation Characteristics of the Modi Taung Gold Deposit, Myanmar. B.Sc Thesis, University of Tasmania, Tasmania.

[4] Lucian, C. and Wangwe, E.M. (2013) The Usefulness of Rock Quality Designation (RQD) in Determining Strength of the Rock. International Refereed Journal of Engineering and Science, 2, 36-40.

[5] Marinos, V., Marinos, P. and Hoek, E. (2005) The Geological Strength Index: Applications and Limitations. Bulletin of Engineering Geology and the Environment, 64, 55-65. https://doi.org/10.1007/s10064-004-0270-5

[6] Hoek, E., Kaiser, P.K. and Bawden, W.F. (2000) Support of Underground Excavations in Hard Rock. Taylor and Francis, p. 9. https://doi.org/10.1201/b16978

[7] Abdellah, W., Mitri, H.S., Thibodeau, D. and Moreau-Verlaan, L. (2014) Geotechnical Risk Assessment of Mine Development Intersections with Respect to Mining Sequence. Geotechnical and Geological Engineering, 32, 657-671. https://doi.org/10.1007/s10706-014-9742-y

[8] Yasitli, N.E. and Unver, B. (2005) 3D Numerical Modeling of Longwall Mining with Top-Coal Caving. International Journal of Rock Mechanics and Mining Sciences, 42, 219-235. https://doi.org/10.1016/j.ijrmms.2004.08.007

[9] Hoek, E. and Brown, E.T. (1997) Practical Estimates of Rock Mass Strength. International Journal of Rock Mechanics and Mining Sciences, 34, 1165-1186. https://doi.org/10.1016/S1365-1609(97)80069-X

[10] Sonmez, H., Gokceoglu, C. and Ulusay, R. (2004) Indirect Determination of the Modulus of Deformation of Rock Masses Based on the GSI System. International Journal of Rock Mechanics and Mining Sciences, 41, 849-857. https://doi.org/10.1016/j.ijrmms.2003.01.006

[11] Karian, T. (2016) Stability Control Measures for Crown Pillar in Cut and Fill Underground Gold Mine under Protected Forest Area, Indonesia. Doctor Thesis, Kyushu University, Japan.

[12] Purwanto. (2015) Design of Support System by Overhand Cut and Fill Mining Method in Underground Gold Mine, Indonesia. Doctor Thesis, Kyushu University, Japan.

[13] Yang, Z., Zhai, S., Gao, Q. and Li, M. (2015) Stability Analysis of Large-Scale Stope Using Stage Subsequent Filling Mining Method in Sijiaying Iron Mine. Journal of 
Rock Mechanics and Geotechnical Engineering, 7, 87-94.

https://doi.org/10.1016/j.jrmge.2014.11.003

[14] Gonen, A. (2011) Stability Analysis of Open Stopes and Backfill in Longhole Stoping Method for Asikoy Underground Copper Mine. Archives of Mining Sciences, 56, No. 3 . 